\title{
A case of cleidocranial dysostosis
}

\author{
W W S D Mendis ${ }^{1}$, P Hewavitharana ${ }^{2}$, S I Samarasekera ${ }^{3}$
}

Sri Lanka Journal of Child Health, 2004; 33: 91-2

(Key words: Cleidocranial dysostosis)

Cleidocranial dysostosis is characterized by varying degree of hypoplasia of membranous bone and to a lesser extent of endochondral bone and dentition ${ }^{1,2}$. It is mainly inherited as autosomal dominant ${ }^{1}$. One third are fresh mutations ${ }^{1}$.

\section{Case report}

A four and half year old girl was admitted to General Hospital, Kalutara for investigation of short stature. Her head circumference was $51 \mathrm{~cm}\left(50^{\text {th }}\right.$ centile), height $90 \mathrm{~cm}\left(<3^{\text {rd }}\right.$ centile), weight $16 \mathrm{~kg}$ (between $10^{\text {th }}$ and $50^{\text {th }}$ centiles). She had a brachycephalic head with open anterior fontanelle. Both clavicles were absent so that she could move her shoulders across the chest. There was no chest deformity. Her dentition was norma ${ }^{1}$.

X-ray skull (figures 1 and 2) showed defective mineralization of the skull bones and widely open fontanelles.There was frontal and parietal bossing with multiple wormian bones. X-ray chest (figure 3) revealed absent clavicles, narrow thorax and short ribs which were obliquely directed downward. Physical features and x-ray findings confirmed the diagnosis of cleidocranial dysostosis.

${ }^{1}$ Consultant Paediatrician, ${ }^{2}$ Consultant Radiologist, ${ }^{3}$ Registrar in Paediatrics, General Hospital, Kalutara.

(Received on 28 August 2003)

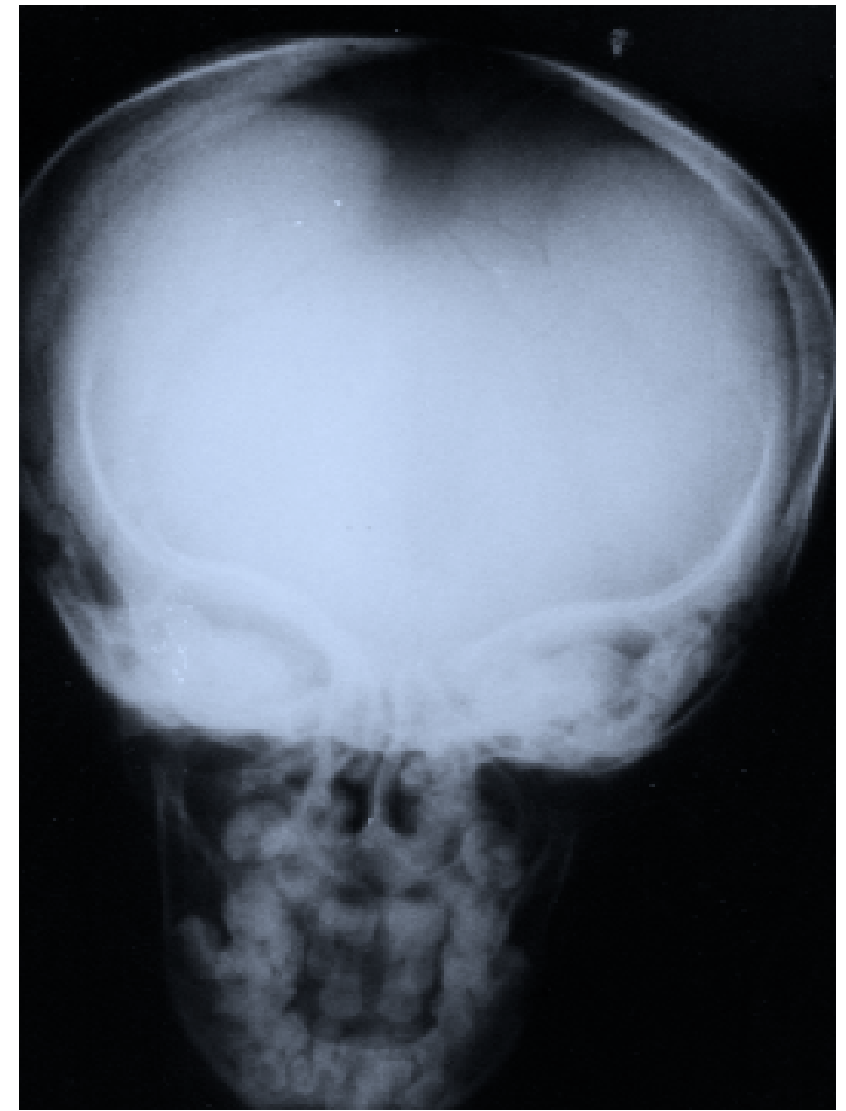

Figure 1. Skull Xray PA 


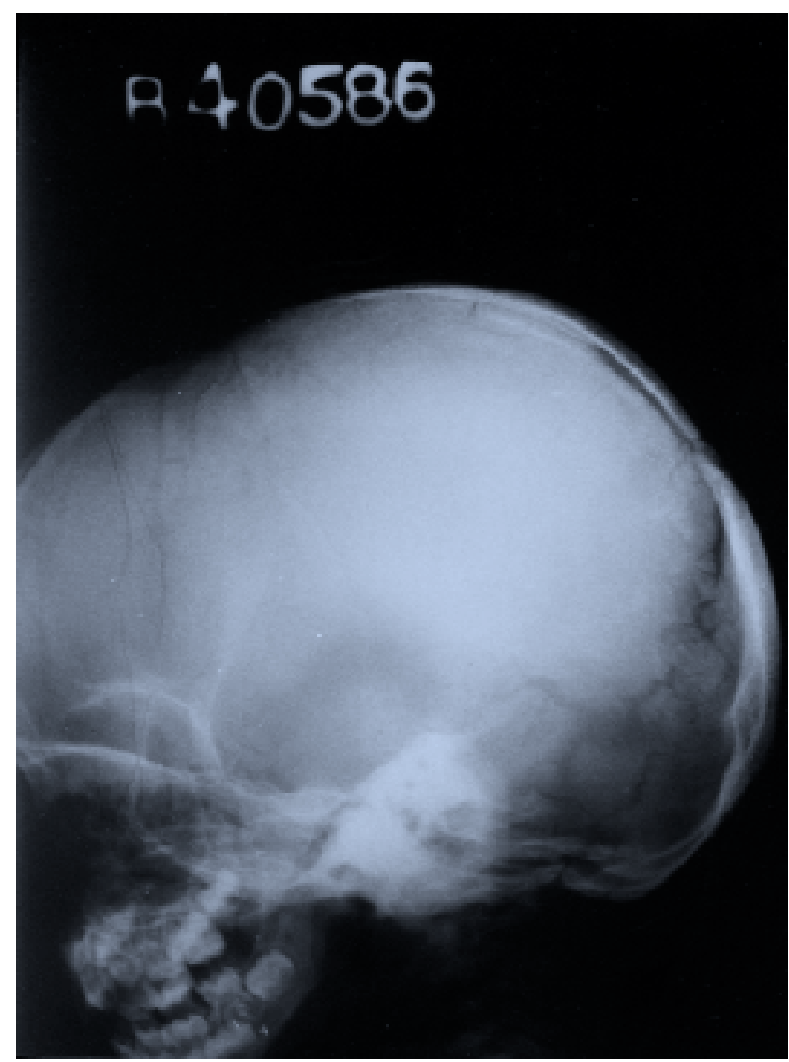

Figure 2. Skull Xray lateral

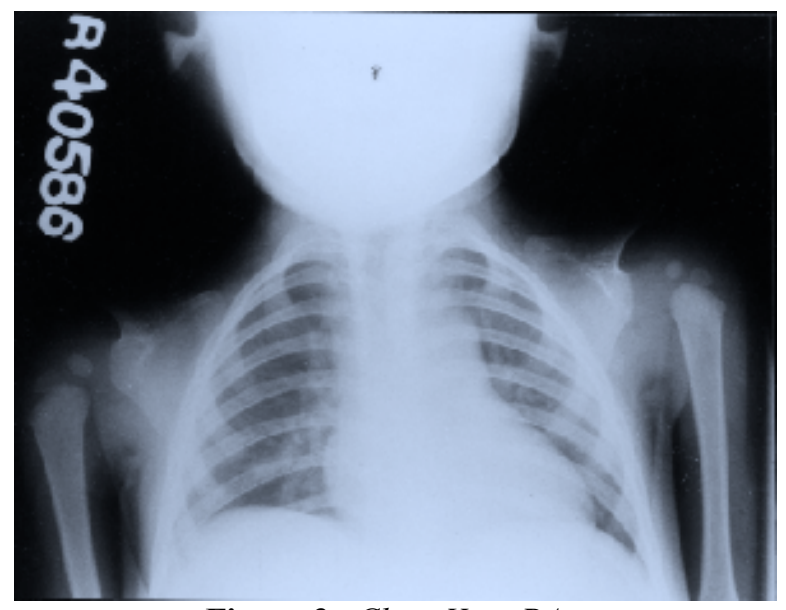

Figure 3. Chest Xray PA

\section{Discussion}

Cleidocranial dysostosis covers a wide range of phenotype variability and deformities are so unobtrusive that the sufferer may not be aware of having the condition ${ }^{2}$. It affects more of the skeleton than the name would imply ${ }^{3}$. It can be suspected clinically even at birth and confirmed by radiological investigations ${ }^{3}$.

Frequently seen abnormalities are short stature, brachycephaly with frontal, parietal, occipital bossing; late closure of fontanelles and mineralization of sutures; incompletely developed accessory sinuses; wormian bones; midfacial hypoplasia with high arched palate; hypoplastic clavicles with small thorax due to short and oblique ribs; asymmetric length of fingers with tapering of distal phalanges; narrow pelvis with wide symphysis pubis; broad femoral head with coxa vara ${ }^{1,2,3}$.

These patients have normal intelligence quotient (IQ) and normal life span ${ }^{1}$. Dental problems, conductive deafness, respiratory distress in early infancy, cephalo-pelvic disproportion necessitating caesarean section are the problems encountered. Although no treatment is available for underlying disorder, multidisciplinary approach for above problems and genetic counselling are of prime importance ${ }^{3}$.

\section{References}

1. Jones K L, editor. Smith's recognizable patterns of human malformation. 5th ed. Philadelphia; W B Saunders, 1997.

2. Sutton D, editor. Textbook of Radiology and Imaging, 5th ed, Edinburgh; Churchill Livingstone, 1993, 14-5.

3. http://www.icondata.com/health/pedbase/files/C LEIDOCR.HTM 


\title{
A case of cleidocranial dysostosis
}

\author{
W W S D Mendis ${ }^{1}$, P Hewavitharana ${ }^{2}$, S I Samarasekera ${ }^{3}$
}

Sri Lanka Journal of Child Health, 2004; 33: 91-2

(Key words: Cleidocranial dysostosis)

Cleidocranial dysostosis is characterized by varying degree of hypoplasia of membranous bone and to a lesser extent of endochondral bone and dentition ${ }^{1,2}$. It is mainly inherited as autosomal dominant ${ }^{1}$. One third are fresh mutations ${ }^{1}$.

\section{Case report}

A four and half year old girl was admitted to General Hospital, Kalutara for investigation of short stature. Her head circumference was $51 \mathrm{~cm}\left(50^{\text {th }}\right.$ centile $)$, height $90 \mathrm{~cm}\left(<3^{\text {rd }}\right.$ centile), weight $16 \mathrm{~kg}$ (between $10^{\text {th }}$ and $50^{\text {th }}$ centiles). She had a brachycephalic head with open anterior fontanelle. Both clavicles were absent so that she could move her shoulders across the chest. There was no chest deformity. Her dentition was normal.

X-ray skull (figures 1 and 2) showed defective mineralization of the skull bones and widely open fontanelles.There was frontal and parietal bossing with multiple wormian bones. X-ray chest (figure 3) revealed absent clavicles, narrow thorax and short ribs which were obliquely directed downward. Physical features and x-ray findings confirmed the diagnosis of cleidocranial dysostosis.

${ }^{1}$ Consultant Paediatrician, ${ }^{2}$ Consultant Radiologist, ${ }^{3}$ Registrar in Paediatrics, General Hospital,

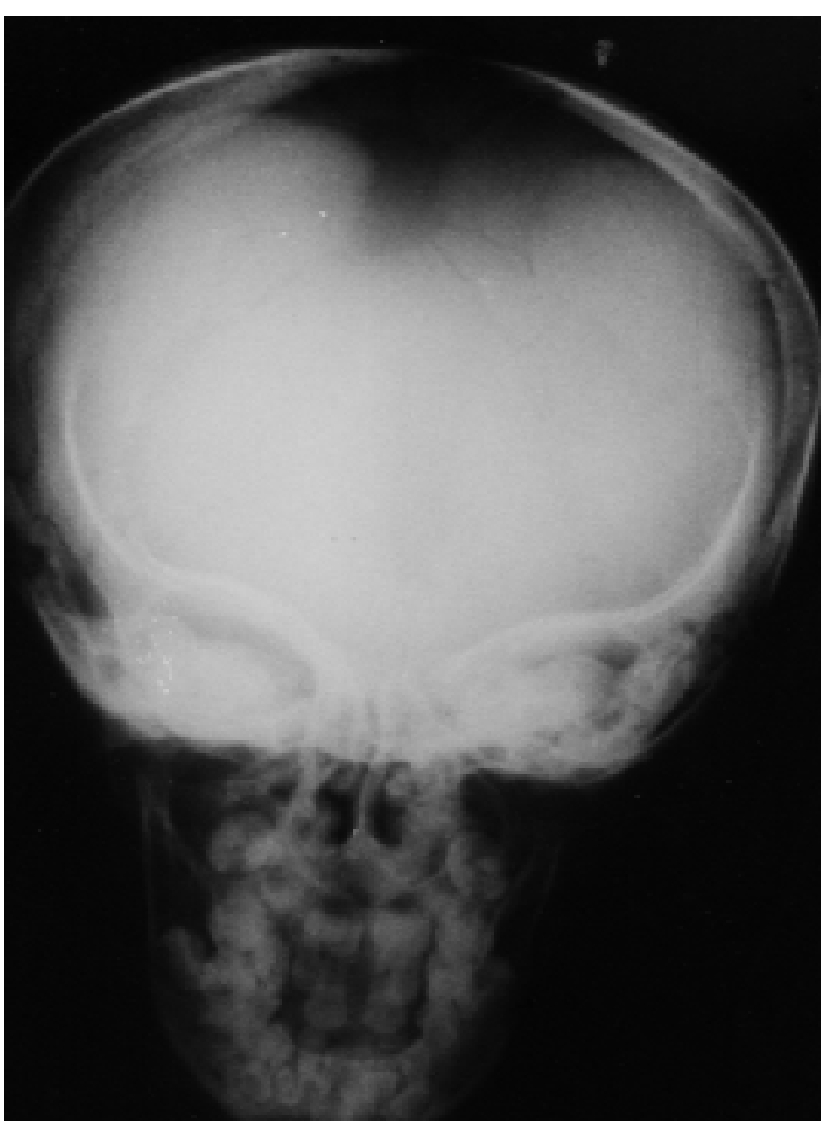

Figure 1. Skull Xray PA Kalutara.

(Received on 28 August 2003) 


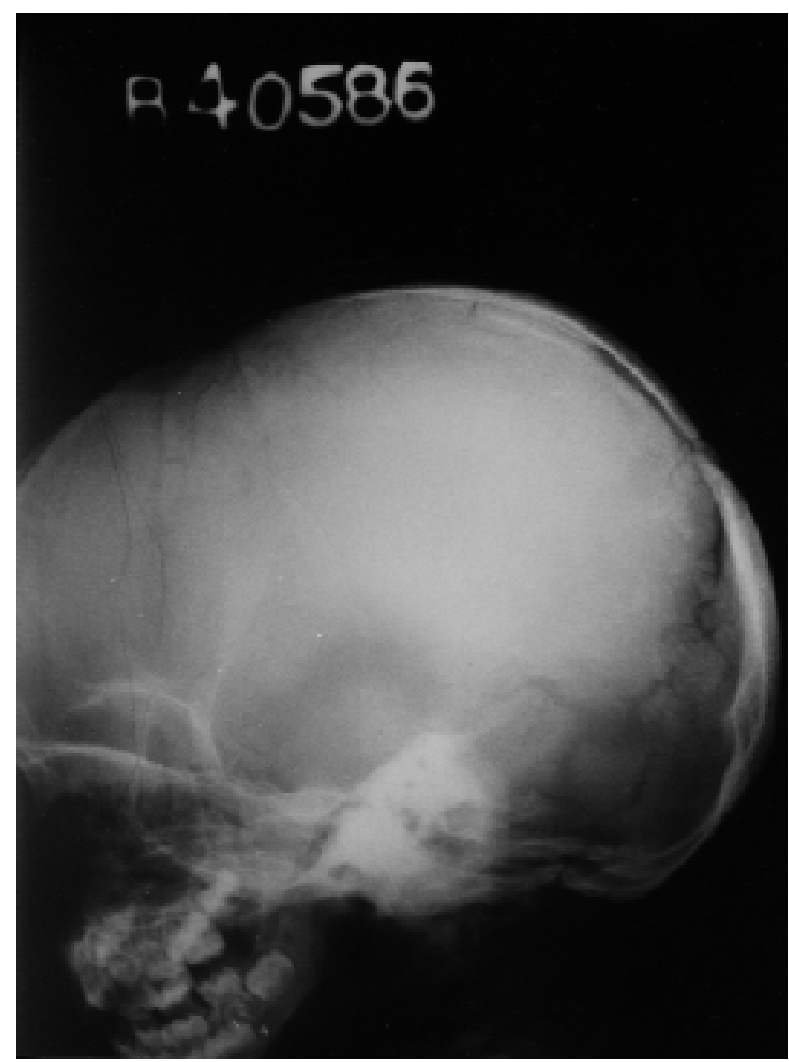

Figure 2. Skull Xray lateral

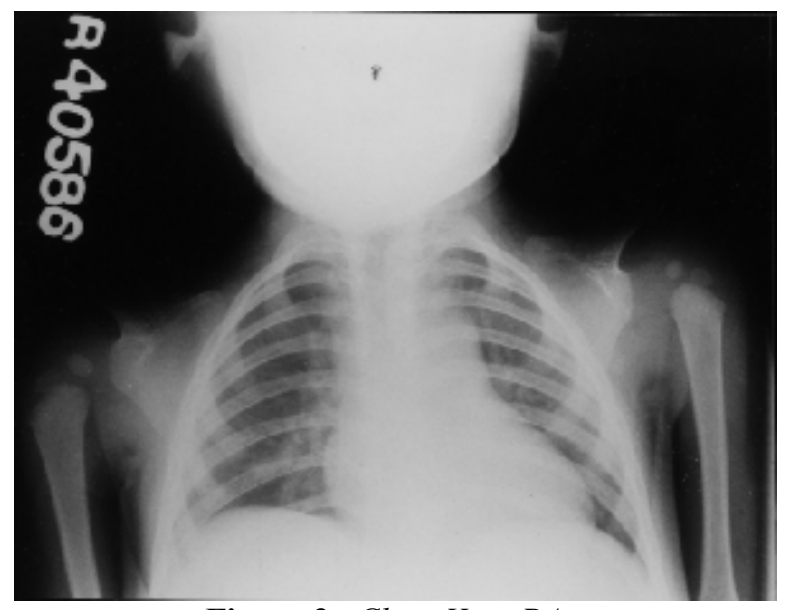

Figure 3. Chest Xray PA

\section{Discussion}

Cleidocranial dysostosis covers a wide range of phenotype variability and deformities are so unobtrusive that the sufferer may not be aware of having the condition ${ }^{2}$. It affects more of the skeleton than the name would imply ${ }^{3}$. It can be suspected clinically even at birth and confirmed by radiological investigations ${ }^{3}$.

Frequently seen abnormalities are short stature, brachycephaly with frontal, parietal, occipital bossing; late closure of fontanelles and mineralization of sutures; incompletely developed accessory sinuses; wormian bones; midfacial hypoplasia with high arched palate; hypoplastic clavicles with small thorax due to short and oblique ribs; asymmetric length of fingers with tapering of distal phalanges; narrow pelvis with wide symphysis pubis; broad femoral head with coxa vara ${ }^{1,2,3}$.

These patients have normal intelligence quotient (IQ) and normal life span ${ }^{1}$. Dental problems, conductive deafness, respiratory distress in early infancy, cephalo-pelvic disproportion necessitating caesarean section are the problems encountered. Although no treatment is available for underlying disorder, multidisciplinary approach for above problems and genetic counselling are of prime importance ${ }^{3}$.

\section{References}

1. Jones K L, editor. Smith's recognizable patterns of human malformation. 5th ed. Philadelphia; W B Saunders, 1997.

2. Sutton D, editor. Textbook of Radiology and Imaging, 5th ed, Edinburgh; Churchill Livingstone, 1993, 14-5.

3. http://www.icondata.com/health/pedbase/files/C LEIDOCR.HTM 